\title{
The Role of Mean Platelet Volume in Pediatric Chronic Kidney Disease Mohamed A. Talat ${ }^{1}$, Naglaa Ali Khalifa ${ }^{2}$, Lamiaa Mahmoud Kamel', Eman Morsy Mohammed ${ }^{3}$ and Hassan Shehata ${ }^{1}$
}

Departments of Pediatrics ${ }^{1}$ and Clinical Pathology ${ }^{2}$, Zagazig University, Ministry of Health ${ }^{3}$, Egypt Corresponding Author: Mohamed Ahmed Talat Kamal, email: Abo.talat@yahoo.com, Tel. No.: +201110455548

\begin{abstract}
Background: Platelets are heterogeneous in size, density, metabolic, functional, and biochemical properties. Mean platelet volume (MPV) is a measure of the average size of platelet in a blood sample.

Objectives: The aim of the work was to study the relationship between MPV levels and the glomerular filtration rate (GFR) in pediatric patients with chronic kidney disease (CKD) and its role to be a marker for the disease progression. Patients and methods: Seventy-five children with chronic kidney disease subdivided into four subgroups according to GFR were included in this study. Seventy-five healthy subjects were enrolled as a control group. All subjects were subjected to detailed history taking, physical examination and Laboratory investigations. Pelvi- abdominal ultrasound used for diagnosis of chronic kidney disease, Tc-99m DTPA (diethylenetriaminepentaacetic acid) scan used for measurement of GFR.
\end{abstract}

Results: MPV levels in the whole patient group were significantly higher than in controls $(9.1 \pm 0.57 \mathrm{fL}$ versus $6.95 \pm 0.63 \mathrm{fL}$ ). There were no significant differences between subgroups of patients with CKD as regard sex, age, weight, systolic, diastolic blood pressure, MPC and PDW while significant differences in disease duration and MPV levels were found among them. In patients with CKD, we have found a significant negative correlation between MPV and GFR. Also, we have found a significant negative correlation between MPV and Mean platelet count per thousand (MPC).

Conclusion: It could be concluded that MPV value can be an easy, rapid, inexpensive, and simple marker for disease progression in pediatric patients with CKD.

Keywords: Mean platelet volume, glomerular filtration rate, Tc-99m DTPA (diethylenetriaminepentaacetic acid) scan.

\section{INTRODUCTION}

Mean platelet volume (MPV) is a measure of the average size of platelet in a blood sample. A high MPV indicates the presence of generally larger platelets and when the MPV is low, platelets are generally smaller. MPV, a readily accessible indicator of platelet activation and function. It is linked with a variety of proinflammatory and prothrombotic conditions. Larger platelets are more possible to aggregate and discharge greater quantities of adhesive particles ${ }^{(\mathbf{1})}$.

Chronic kidney disease (CKD) is identified by the occurrence of kidney damage; either structural or functional and characterized by progressive and irreversible deterioration of the renal excretory function and/or glomerular filtration rate (GFR) below 60 $\mathrm{mL} / \mathrm{min} / 1.73 \mathrm{~m} 2$ of body surface area for more than three months ${ }^{(2)}$.

$\mathrm{CKD}$ is associated with a variety of proinflammatory and prothrombotic conditions. Elevated MPV in patients with CKD may reveal the chronic inflammatory status of $\mathrm{CKD}^{(3)}$.

One study has been investigated MPV in pediatric patients with CKD but the authors involved a disease control with upper respiratory tract (URT) inflammatory signs due to difficulty to recruit normal pediatric patients and they did not investigate the role of MPV in reflection of disease progression ${ }^{(4)}$.
The aim of the current work was to study the relationship between MPV levels and the GFR in pediatric patients with CKD and its role to be a marker for the disease progression.

\section{PATIENTS and METHODS}

This case control study included a total of 150 children with age range 2 to 17 year, attending at pediatric nephrology unit and general pediatric outpatient clinic, Zagazig University Hospitals. This study was conducted between July 2018 and December 2019.

Ethical approval: Approval of the Ethical Committee of Zagazig University was obtained. It is consistent with the principles of the Declaration of Helsinki. Written informed consent of all the parents of subjects was obtained; included the required information about this study.

The included subjects were divided into two groups; Group A (chronic kidney disease) consisted of 75 children. They were further subdivided into four subgroups according to GFR calculated by DTPA scan (5): Subgroup (1): Mild CKD (GFR $=60-89$ 
$\mathrm{mL} / \mathrm{min} / 1.73 \mathrm{~m} 2$ ), Subgroup (2): Moderate CKD (GFR $=30-59 \mathrm{~mL} / \mathrm{min} / 1.73 \mathrm{~m} 2)$.

Subgroup (3): Severe CKD (GFR $=15-29 \mathrm{~mL} / \mathrm{min} / 1.73$ $\mathrm{m} 2$ ), and Subgroup (4): End Stage CKD (GFR <15 $\mathrm{mL} / \mathrm{min} / 1.73 \mathrm{~m} 2$ ) and Group B (Control) consisted of 75 healthy subjects from general pediatric outpatient clinic enrolled as a control group.

Exclusion Criteria: Patients with coronary artery disease, metabolic diseases as diabetes mellitus, cases of thromboembolic diseases, malignancy and patients on drugs affecting platelet function and statins were not included in the study.

All patients and controls were subjected to:

1- Full history taking including age, sex, age at time of diagnosis, duration of disease, co-morbidities, medications.

2- Full physical examination including weight, height, body mass index and surface area with blood pressure assessment (systolic and diastolic).

3- Laboratory investigations: Blood and urine samples were taken from children with chronic kidney disease after making DPTA scan. Blood samples were used for doing 1) Complete blood count (CBC): including RBCs count, hemoglobin concentration, MPV, Mean platelet count per thousand (MPC) and platelet distribution width (PDW) using Sysmex- Xs-500 i (Sysmex Corporation -Japan). 2) Other blood chemistry: Kidney function tests (urea \& creatinine), albumin, total cholesterol, and C-reactive protein (CRP) on Cobas 8000 C 702, Roch, Germany; 3) Prothrombin time and partial thromboplastin time by (Sysmex Cs 2500) device. 4) Erythrocyte sedimentation rate (ESR) which measured manually. The urine samples were obtained from patients in the early morning by one of the two techniques, either a clean catch mid-stream method or urinary catheterization method using 8 French polyethylene feeding tube. The urine samples were put into sterile containers then centrifuged for $20 \mathrm{~min}$. The urinary collection samples were reserved into sterile containers refrigerated at $2^{\circ} \mathrm{C}-8^{\circ} \mathrm{C}$ and then the samples were re-warmed to room temperature just before laboratory assessment ${ }^{(\boldsymbol{(})}$.

4- Radiological investigations:

5- Pelvi-abdominal ultrasound used for diagnosis of chronic kidney disease, Tc-99m DTPA (diethylenetriaminepentaacetic acid) scan used for measurement of GFR.

\section{Statistical Analysis}

Data were checked, entered and statistically analyzed by SPSS (Statistical Package for Social Sciences version 20, Chicago, IL, USA).

Data were expressed as a mean \pm standard deviation for quantitative variables or number and percentage for categorical variables.
Percent of categorical variables were compared using Chi-square test. T test was used to compare between two groups of normally distributed variables. Mann Whitney U test was used to compare between two groups of non-normally distributed variables. One-way ANOVA test was used to compare between more than two dependent groups of normally distributed variables while Kruskall Wallis test ranks test was used for nonnormally distributed variables. Paired t test was used to compare between two dependent variables of normally distributed variables. Wilcoxon Signed Ranks Test was used to compare between two dependent variables of non-normally distributed variables.

Pearson's and Spearman's correlation tests were used for correlating normal and non-parametric variables respectively. All statistical comparisons were two tailed with significance Level of P-value $\leq 0.05$ indicates significant, $\mathrm{p}<0.001$ indicates highly significant difference while, $\mathrm{P}>0.05$ indicates nonsignificant difference.

\section{RESULTS}

Our study included 75 patients with CKD (M/F: $31 / 44$ ) with the mean age was $10.6 \pm 3$ years and 75 healthy children (M/F: 33/42) with the mean age was $9.1 \pm 2.8$ years. Results revealed no significant difference between the three studied groups as regard age, sex.

MPV levels in the whole patient group were significantly higher than in controls $(9.1 \pm 0.57 \mathrm{fL}$ versus $6.95 \pm 0.63 \mathrm{fL}$, respectively, $\mathrm{p}<0.001)$. PDW levels in the whole patient group were significantly higher than in controls $(21 \pm 4.9 \mathrm{fL}$ versus $15 \pm 1.1 \mathrm{fL}$, respectively, $\mathrm{p}=0.04)$. There were no significant differences in MPC between whole patient group and controls.

Table 1 shows no significant differences between subgroups of patients with CKD as regard sex, age, weight, systolic, diastolic blood pressure, MPC and PDW while a significant differences in disease duration and MPV levels were found among them.

In patients with CKD, there was a significant positive correlation between MPV on one hand and serum creatinine, disease duration on the other hand. A significant negative correlation between MPV and GFR was found as shown in table 2 and figure 1.

In patients with CKD, we found a significant positive correlation between MPC and GFR ( $r=0.54$, $\mathrm{p}=0.004)$. A significant positive correlation between PDW on one hand and serum urea, creatinine, albumin on the other hand was found in patients with CKD as shown in table 3.

We found a significant negative correlation between MPV and MPC in patients with CKD $(r=-0.53$, $\mathrm{p}=0.0$ ). No significant correlations between MPV and PDW or between MPC and PDW in patients with CKD were found as shown in table 4. 
Table (1): Comparison of different stages of chronic kidney disease in terms of history, demographic data, and laboratory results

\begin{tabular}{|c|c|c|c|c|c|c|c|}
\hline \multirow{2}{*}{\multicolumn{2}{|c|}{ Mean \pm SD }} & \multicolumn{4}{|c|}{ Patients with chronic kidney diseases $(n=75)$} & \multirow{3}{*}{$\begin{array}{c}\text { Test } \\
\text { sign }\end{array}$} & \multirow{3}{*}{$\begin{array}{l}\mathbf{p} \\
0.3\end{array}$} \\
\hline & & \multirow{2}{*}{$\begin{array}{l}\begin{array}{l}\text { CKD 1 } \\
(n=12)\end{array} \\
6 / 6\end{array}$} & \multirow{2}{*}{$\begin{array}{l}\begin{array}{l}\text { CKD 2 } \\
(n=20)\end{array} \\
8 / 12\end{array}$} & \multirow{2}{*}{$\begin{array}{l}\begin{array}{l}\text { CKD 3 } \\
(n=22)\end{array} \\
9 / 13\end{array}$} & \multirow{2}{*}{$\begin{array}{l}\begin{array}{l}\text { CKD } 4 \\
(n=21)\end{array} \\
8 / 13\end{array}$} & & \\
\hline SEX & $\begin{array}{l}\mathrm{M} / \mathrm{F} \\
\text { ratio }\end{array}$ & & & & & & \\
\hline \multicolumn{2}{|c|}{ Age (years) } & $10 \pm 2.8$ & $10.3 \pm 4$ & $9.5 \pm 5$ & $13.3 \pm 2.3$ & KW & 0.18 \\
\hline \multicolumn{2}{|c|}{ Weight/kg } & $26.5 \pm 0.71$ & $27.7 \pm 11$ & $25.3 \pm 9.7$ & $28.8 \pm 9$ & KW & 0.08 \\
\hline \multicolumn{2}{|c|}{$\begin{array}{l}\begin{array}{l}\text { Diastolic BP } \\
(\mathrm{mmHg})\end{array} \\
\end{array}$} & $65 \pm 7$ & $77 \pm 14$ & $75 \pm 10$ & $75 \pm 10$ & $\mathrm{~F}$ & 0.48 \\
\hline \multicolumn{2}{|c|}{$\begin{array}{l}\text { Systolic BP } \\
(\mathrm{mmHg})\end{array}$} & $100 \pm 5$ & $117 \pm 19$ & $117 \pm 8$ & $115 \pm 5$ & $\mathrm{~F}$ & 0.09 \\
\hline \multicolumn{2}{|c|}{$\begin{array}{l}\text { Disease } \\
\text { duration/years }\end{array}$} & $2.5 \pm 2$ & $3 \pm 0.9$ & $3.5 \pm 2.2$ & $4.7 \pm 1.5$ & KW & $\mathbf{0 . 0 3}$ \\
\hline \multicolumn{2}{|c|}{$\begin{array}{l}\text { Mean platelet } \\
\text { volume (fL) }\end{array}$} & $7.45 \pm 0.53$ & $7.75 \pm 0.55$ & $8.4 \pm 0.8$ & $9.2 \pm 0.84$ & $\mathrm{~F}$ & $<0.001$ \\
\hline \multicolumn{2}{|c|}{$\begin{array}{l}\text { Mean platelet } \\
\text { count }\left(\mathbf{1 0}^{9} / \mathrm{L}\right)\end{array}$} & $332 \pm 179$ & $282 \pm 86$ & $236 \pm 10$ & $198 \pm 93$ & KW & 0.09 \\
\hline \multicolumn{2}{|c|}{$\begin{array}{l}\begin{array}{l}\text { Platelet } \\
\text { distribution width } \\
(\%)\end{array} \\
\end{array}$} & $18.5 \pm 16$ & $21 \pm 12.3$ & $22 \pm 11$ & $23.3 \pm 9$ & $\mathrm{KW}$ & 0.89 \\
\hline
\end{tabular}

Values are presented as mean \pm standard deviation or number $(\%)$.

$\mathrm{KW}=$ Kruskall Wallus test $\quad \chi 2=$ chi square $\quad \mathrm{F}=$ ANOVA test

$\mathrm{P}<0.001$ is highly significant, $\mathrm{P}<0.05$, is significant, $\mathrm{P}>0.05$, is non-significant

Table (2): Correlation between mean platelet volume levels and laboratory results of the two studied groups

\begin{tabular}{|c|c|c|c|c|}
\hline \multirow[t]{2}{*}{ Mean platelet volume } & \multicolumn{2}{|c|}{$\begin{array}{l}\text { Patients with chronic kidney } \\
\text { diseases }(n=75)\end{array}$} & \multicolumn{2}{|c|}{$\begin{array}{l}\text { Control } \\
(\mathrm{n}=75)\end{array}$} \\
\hline & $\mathbf{r}$ & p & $\mathbf{r}$ & $p$ \\
\hline HB & 0.24 & 0.28 & 0.21 & 0.3 \\
\hline WBCs & -0.394 & 0.063 & -0.12 & 0.5 \\
\hline RBCs & 0.24 & 0.27 & 0.1 & 0.7 \\
\hline CRP & -0.31 & 0.147 & -0.05 & 0.8 \\
\hline ESR2 & 0.06 & 0.79 & 0.4 & 0.5 \\
\hline ESR1 & 0.005 & 0.98 & 0.61 & 0.07 \\
\hline Serum Urea & 0.159 & 0.47 & 0.3 & 0.1 \\
\hline Serum Creatinine & 0.61 & 0.002 & 0.17 & 0.4 \\
\hline Serum Albumin & 0.23 & 0.29 & 0.24 & 0.26 \\
\hline glomerular filtration rate (GFR) & -0.9 & $<0.001$ & -0.34 & 0.07 \\
\hline Disease duration & 0.49 & $\mathbf{0 . 0 3}$ & - & - \\
\hline
\end{tabular}

$\mathrm{P}<0.001$ is highly significant, $\mathrm{P}<0.05$, is significant, $\mathrm{P}>0.05$, is non-significant

Table (3): Correlation between platelet distribution width levels and laboratory results of the two studied groups 


\begin{tabular}{|l|l|l|l|l|}
\hline Platelet distribution width & \multicolumn{3}{l|}{$\begin{array}{l}\text { Patients with chronic kidney } \\
\text { diseases }\end{array}$} & \multicolumn{2}{l|}{$\begin{array}{l}\text { Control } \\
(\mathbf{n = 7 5})\end{array}$} \\
\hline & $\mathbf{r}$ & $\mathbf{P}$ & $\mathbf{r}$ & $\mathbf{P}$ \\
\hline HB & -0.26 & 0.24 & 0.22 & 0.3 \\
\hline WBCs & -0.16 & 0.47 & -0.13 & 0.49 \\
\hline RBCs & -0.101 & 0.65 & 0.103 & 0.63 \\
\hline CRP & 0.134 & 0.54 & -0.04 & 0.7 \\
\hline ESR2 & -0.02 & 0.93 & 0.45 & 0.5 \\
\hline ESR1 & -0.053 & 0.81 & 0.7 & 0.06 \\
\hline Serum Urea & 0.69 & $<\mathbf{0 . 0 0 1}$ & 0.35 & 0.09 \\
\hline Serum Creatinin & 0.48 & $\mathbf{0 . 0 2}$ & 0.15 & 0.41 \\
\hline Serum Albumin & 0.5 & $\mathbf{0 . 0 1 4}$ & 0.25 & 0.25 \\
\hline glomerular filtration rate (GFR) & 0.034 & 0.88 & -0.36 & 0.06 \\
\hline Disease duration & -0.18 & 0.45 & - & - \\
\hline
\end{tabular}

$\mathrm{P}<0.001$ is highly significant, $\mathrm{P}<0.05$, is significant, $\mathrm{P}>0.05$, is non-significant

Table (4): Correlation between mean platelet volume levels, mean platelet count, and platelet distribution width levels of the two studied groups

\begin{tabular}{|c|c|c|c|c|c|c|c|c|}
\hline & \multicolumn{4}{|c|}{$\begin{array}{c}\text { Patients with chronic kidney diseases } \\
(n=75)\end{array}$} & \multicolumn{4}{|c|}{$\begin{array}{c}\text { Control } \\
(n=75)\end{array}$} \\
\hline & \multicolumn{2}{|c|}{$\begin{array}{l}\text { Mean platelet } \\
\text { count }\end{array}$} & \multicolumn{2}{|c|}{$\begin{array}{l}\text { Platelet distribution } \\
\text { width }\end{array}$} & \multicolumn{2}{|c|}{$\begin{array}{l}\text { Mean platelet } \\
\text { count }\end{array}$} & \multicolumn{2}{|c|}{$\begin{array}{l}\text { Platelet } \\
\text { distribution width }\end{array}$} \\
\hline & $\mathbf{r}$ & $\mathbf{p}$ & $\mathbf{r}$ & p & $\mathbf{r}$ & p & $\mathbf{r}$ & p \\
\hline $\begin{array}{l}\text { Mean platelet } \\
\text { volume }\end{array}$ & -0.53 & 0.01 & 0.13 & 0.56 & -0.14 & 0.54 & 0.39 & 0.08 \\
\hline Mean platelet count & & & -0.36 & 0.1 & & & 0.2 & 0.4 \\
\hline
\end{tabular}

$\mathrm{P}<0.001$, highly significant; $\mathrm{P}<0.05$, significant; $\mathrm{P}>0.05$, non-significant

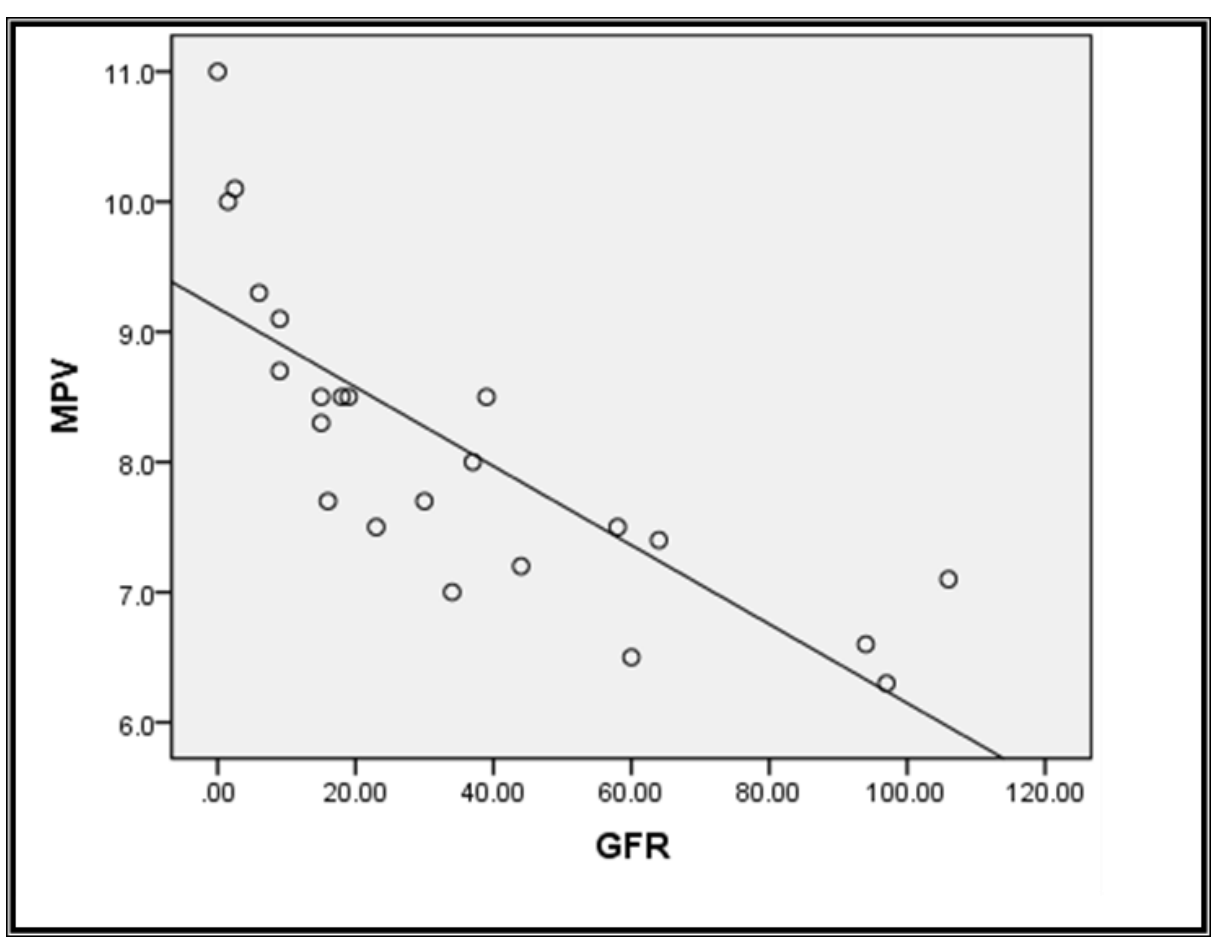

Figure legends

Figure (1): Correlation between mean platelet volume (MPV) and glomerular filtration rate (GFR) of chronic kidney disease patients.

\section{DISCUSSION}

MPV has been revealed to reflect the inflammatory load and disease activity in several chronic inflammatory conditions. There is also a 
recognized consensus regarding the link between inflammation and platelet stimulation ${ }^{(7)}$.

MPV and MPC values were significantly higher in patients with CKD than control group and this agree with Koroglu et al. ${ }^{\left({ }^{(8)}\right.}$ who observe high MPV in CKD and concluded that it can be used to estimate atherosclerosis risk in CKD patients. But, this disagree with Yilmaz et al. ${ }^{\left({ }^{9}\right)}$ who studied the mean platelet volume in CKD stage 3-4 and found insignificant difference between 53 adult patient and 30 control in platelet parameters.

Increased MPV in patients with CKD may reveal the chronic inflammatory status of CKD. Sakalli et al. (10) stated that the MPV reduced after renal transplantation and suggested the existence of a chronic inflammatory status because chronic kidney disease had improved after kidney transplantation.

When we compared MPV, MPC and PDW among different grades of CKD, we have found a significant difference among them in MPV but no significant difference in MPC count and PDW. This agrees with study done by Ju et al. ${ }^{(3)}$ on 553 adults with CKD and they found that the MPV rises according to the CKD stage and showed a significant intergroup difference but there were no significant differences regarding MPC.

We have found a significant positive correlation between MPV and serum creatinine and disease duration that agree with $\mathbf{J u}$ et al. ${ }^{(3)}$ but disagree with Tamadon et al. ${ }^{(11)}$ found that the negative relation between MPV and serum creatinine. We found a significant negative correlation between MPV and GFR that agree with previous studies ${ }^{\mathbf{3 , 9}}$.

We found a significant positive correlation between MPC with GFR. This agrees with Ju et al. ${ }^{(3)}$ We found a significant positive correlation between PDW and serum urea, creatinine and albumin but no significant correlation with GFR. This disagrees with Ju et al. ${ }^{(3)}$ who found that PDW decreased along with eGFR.

Our study revealed a significant negative correlation of MPV and PLT count in CKD patients. This disagrees with Yilmaz et al. ${ }^{(9)}$ who found a positive correlation between MPV and PLT count. The inverse relationship between platelet count and MPV has been reported frequently in physiological and some pathological situations. This reveals the tendency to conserve hemostasis by preserving a constant platelet mass ${ }^{(\mathbf{1})}$.

\section{CONCLUSION}

It could be concluded that MPV was higher in patients with progressive CKD than in those with early stage CKD. MPV value could be used as an easy, rapid, inexpensive, and simple marker for the monitoring of disease progression in patient with CKD.

\section{ACKNOWLEDGEMENTS}

The authors thank the staff of our university children's hospital for their collaboration as well as the parents of children's who accepted to participate in the study.

\section{REFERENCES}

1. Gasparyan AY, Ayvazyan L, Mikhailidis D et al. (2011): Mean platelet volume: A link between thrombosis and inflammation? Curr Pharm Des., 17:47-58.

2. Kidney Disease Outcomes Quality Initiative (2013): 2012 Clinical Practice Guideline for the Evaluation and Management of Chronic Kidney Disease Kidney Int Suppl., $3: 1-150$.

3. Ju HY, Kim JK, Hur SM et al. (2015): Could mean platelet volume be a promising biomarker for chronic kidney disease? Platelets, 26(2):143-147.

4. Cho SY, Suh JS, Cho BS et al. (2013): Mean platelet volume in pediatric chronic kidney diseases. Platelets, 24(2):164-165.

5. Kidney Disease Outcomes Quality Initiative (2009): Clinical Practice Guideline for Nutrition in Children with CKD update. Executive summary. Am J Kidney Dis., 53(2):S11-104.

6. Vaidya VS, Waikar SS, Ferguson MA et al. (2008): Urinary biomarkers for sensitive and specific detection of acute kidney injury in humans. Clin Transl Sci., 1:200-208.

7. Yazici S, Yazici M, Erer B et al. (2010): The platelet indices in patients with rheumatoid arthritis: Mean platelet volume reflects disease activity. Platelets, 21(2):122-125.

8. Koroglu M, Akalin N, Ozkhan H et al. (2015): Importance of platelet markers for demonstrating the presence of inflammation in different stages of chronic kidney diseases .Eur J Basic Med Sci., 5(1):1-9.

9. Yilmaz G, Sevinc C, Ustundag S et al. (2017): The relationship between the mean platelet volume and neutrophill lymphocyte ratio with inflammation and protinuria in chronic kidney disease. Saudi J Kidney Dis Transpl., 28(1):90-94.

10. Sakalli H, Baskin E, Bayrakc US et al. (2013): Mean platelet volume as a potential predictor of renovascular thrombosis after renal transplant. Exp Clin Transplant., 11(1):27-31.

11. Tamadon MR, Torabi SMA, Moghimi J et al. (2018): Serum creatinin level in relationship with mean platlet volume in patients with chronic kidney disease. J Renal Inj Prew., 7(1):38-41. 